\title{
Rapid Antiretroviral Therapy (ART) Initiation at a Community-Based Clinic in Jackson, MS
}

\author{
Courtney E. Sims Gomillia ${ }^{1 *+}$ D, Kandis V. Backus ${ }^{1,2^{*}+}$, James B. Brock ${ }^{2}$, Sandra C. Melvin ${ }^{3}$, Jason J. Parham ${ }^{1,2}$
} and Leandro A. Mena ${ }^{1,2}$

\begin{abstract}
Background: Rapid antiretroviral therapy (ART), ideally initiated within twenty-four hours of diagnosis, may be crucial in efforts to increase virologic suppression and reduce HIV transmission. Recent studies, including demonstration projects in large metropolitan areas such as Atlanta, Georgia; New Orleans, Louisiana; San Francisco, California; and Washington D.C., have demonstrated that rapid ART initiation is a novel tool for expediting viral suppression in clinical settings. Here we present an evaluation of the impact of a rapid ART initiation program in a community-based clinic in Jackson, MS.
\end{abstract}

Methods: We conducted a retrospective chart review of patients who were diagnosed with HIV at Open Arms Healthcare Center or were linked to the clinic for HIV care by the Mississippi State Department of Health Disease Intervention Specialists from January 1, 2016 to December 31, 2018. Initial viral load, CD4+T cell count, issuance of an electronic prescription (e-script), subsequent viral loads until suppressed and patient demographics were collected for each individual seen in clinic during the review period. Viral suppression was defined as a viral load less than 200 copies/mL. Rapid ART initiation was defined as receiving an e-script for antiretrovirals within seven days of diagnosis.

Results: Between January 1, 2016 and December 31, 2018, 70 individuals were diagnosed with HIV and presented to Open Arms Healthcare Center, of which 63 (90\%) completed an initial HIV counseling visit. Twenty-seven percent of patients were provided with an e-script for ART within 7 days of diagnosis. The median time to linkage to care for this sample was 12 days and 5.5 days for rapid ART starters $(p<0.001)$. Median time from diagnosis to viral suppression was 55 days for rapid ART starters $(p=0.03)$, a 22 day decrease from standard time to viral suppression.

Conclusion: Our results provide a similar level of evidence that rapid ART initiation is effective in decreasing time to viral suppression. Evidence from this evaluation supports the use of rapid ART initiation after an initial HIV diagnosis, including same-day treatment.

Keywords: Rapid ART, Immediate ART, HIV treatment, Viral suppression

\section{Background}

Rapid antiretroviral therapy (ART) is a novel strategy to reduce HIV transmission and shorten time to virologic suppression. Rapid ART has been adopted

\footnotetext{
*Correspondence: cegomillia@umc.edu

${ }^{\dagger}$ Courtney E. Sims Gomillia, Kandis V. Backus share first authorship ${ }^{1}$ Department of Population Health Science, John D. Bower School of Population Health, University of Mississippi Medical Center, $2500 \mathrm{~N}$ State Street, Jackson, MS 39216, USA

Full list of author information is available at the end of the article
}

in many cities throughout the United States and typically involves the provision of antiretroviral medications within 7 days of a new diagnosis. Rapid ART, ideally within 24-h of diagnosis, is proving to be crucial in efforts to speed virologic suppression and reduce HIV transmission [1-7]. Our national plan: "Ending the HIV Epidemic: A Plan for America" aims to improve quality of life for people living with HIV (PLWH) through early diagnosis and rapid and effective treatment to achieve and maintain viral

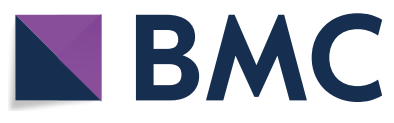

(C) The Author(s) 2020. This article is licensed under a Creative Commons Attribution 4.0 International License, which permits use, sharing, adaptation, distribution and reproduction in any medium or format, as long as you give appropriate credit to the original author(s) and the source, provide a link to the Creative Commons licence, and indicate if changes were made. The images or other third party material in this article are included in the article's Creative Commons licence, unless indicated otherwise in a credit line to the material. If material is not included in the article's Creative Commons licence and your intended use is not permitted by statutory regulation or exceeds the permitted use, you will need to obtain permission directly from the copyright holder. To view a copy of this licence, visit http://creativeco mmons.org/licenses/by/4.0/. The Creative Commons Public Domain Dedication waiver (http://creativecommons.org/publicdomain/ zero/1.0/) applies to the data made available in this article, unless otherwise stated in a credit line to the data. 
suppression $[8,9]$. Recommendations that ART should be initiated within 7 days of HIV diagnosis have been adopted by the World Health Organization (WHO) and International AIDS Society-USA (IAS-USA) [1, 3]. The Department of Health and Human Services (DHHS) also recommends the immediate initiation of ART therapy due to the significant increase in viral suppression amongst patients from the START and TEMPRANO randomized trials who began immediate ART or initiated therapy within 7 days [10].

Recent trials have demonstrated the benefits of starting ART as soon as possible following HIV diagnosis [1, 2, 4,11 ]. Findings from the HPTN 052 trial informed the treatment as prevention strategy to combat HIV infection [12]. Evidence provided by the PARTNER and Opposites Attract prospective, observational studies support that the risk of HIV transmission in both gay and heterosexual couples through condomless sex when HIV viral load is undetectable is effectively zero $[13,14]$. Moreover, earlier linkage to care and treatment has proven to improve patient outcomes and decrease AIDS progression and mortality [15].

Recent demonstration projects in large metropolitan areas such as Atlanta (ATL), New Orleans (NO), San Francisco (SF) and Washington D.C. (DC) have demonstrated that rapid ART initiation is a promising strategy for earlier virologic suppression in clinical settings $[6,7,16]$. Each of these cities benefitted from citywide and statewide initiatives to end HIV that promote faster linkage, greater access to care, expedited clinic intake and increased fiscal resources for rapid initiation. Median time to virologic suppression following ART initiation in ATL, NO, and SF was 57 days, 30 days, and 43 days, respectively $[1,6,7]$. The Fast Forward (FF) pilot program in DC did not see a significant difference between time from diagnosis to viral suppression between individuals who were in the FF group compared to standard of care (SOC) $(80.6 \%$ vs. $74.2 \%$ ) [16]. However, this could be attributed to the wraparound services (i.e. insurance navigation, phlebotomy, nursing intake, and medical assessment) already included in their existing SOC model.

Barriers including poverty, housing insecurities and lack of health insurance impact linkage to care and can delay initiation of ART. Other structural barriers to rapid ART initiation include the absence of Medicaid expansion in the state of Mississippi and the process of approval for ART medications through the AIDS Drug Assistance Program (ADAP). The latter requires that new HIV diagnoses be registered in the Enhanced HIV/ AIDS Reporting System (eHARS) with documentation of $\mathrm{CD} 4+\mathrm{T}$ cell count and HIV viral load results which may take up to 14 days to be reported. These requirements can interfere with same-day access to HIV medications, especially for underinsured or uninsured individuals.

Open Arms Healthcare Center (OAHCC) is a community-based clinic in Jackson, Mississippi offering primary care services with an emphasis on the healthcare needs of gender and sexual minority populations. OAHCC has provided holistic HIV care since 2014 and has been a regional innovator of HIV service delivery since its inception. In January 2016, OAHCC began offering same-day ART initiation for newly diagnosed patients, dependent on each individuals' willingness to start. The purpose of this analysis was to evaluate the impact of rapid ART initiation in a community-based clinic that provides primary HIV care in a city with high incidence and prevalence of HIV. In this evaluation, we compared the outcomes (viral loads and CD4+ T cell counts) of individuals who initiated ART within 7 days of receiving an HIV diagnosis (rapid ART) with those who did not (non-rapid starters).

\section{Methods \\ Study setting}

This study was conducted at Open Arms Healthcare Center (OAHCC), a community-based organization (CBO) under the direction of My Brother's Keeper, Incorporated. OAHCC was incepted in 2012 with a mission focused on providing a safe space that offers holistic healthcare to Lesbian, Gay, Bisexual and Transgender (LGBT) individuals. The first HIV clinic began in 2014 and has grown to more than 400 established patients.

\section{Study design}

We conducted a retrospective review of medical records of individuals newly diagnosed with HIV who presented to OAHCC for HIV care and treatment from January 1, 2016 through December 31, 2018. Patients either were diagnosed with HIV at OAHCC or referred for linkage to HIV treatment services from the Mississippi State Department of Health (MSDH) Sexually Transmitted Disease (STD) Clinic by a Disease Intervention Specialist after being notified of their HIV diagnosis. Initial clinic visits at OAHCC included clinical evaluation (i.e. nursing intake and phlebotomy), HIV-related education and counseling, enrollment in the Ryan White Part B program and ADAP, if applicable, and baseline laboratory tests. Patients were prescribed medication on the same day of their initial clinical visit when possible, depending on their expressed willingness and medication coverage. Uninsured patients were given access to medications through available medication samples or access through drug manufacturer medication assistance programs. The following variables were abstracted from the medical records by OAHCC staff 
during and included demographics, date of HIV diagnosis, date of first visit to a provider at OAHCC, risk factor(s) for HIV acquisition, drug use, insurance status and date of and results for initial and subsequent HIV viral load and CD4+ T cell counts.

Rapid ART starters were defined as individuals who started ART within seven days of an initial HIV diagnosis; all others were classified as non-rapid starters. Manufacturer-funded drug assistance programs were used to provide immediate access to ART pending commercial insurance or ADAP approval at no additional cost to patients. Primary statistical analyses compared time from ART initiation to viral suppression amongst rapid ART starters and non-rapid starters. Secondary analyses were used to determine differences in time from diagnosis to viral suppression between the two groups as well as well as the effect time from diagnosis to treatment initiation had on viral suppression.

\section{Study measures and analysis}

We compared outcomes data per year (2016-2018) and between groups. Viral suppression was defined as HIV RNA $<200$ copies/mL. Date of ART initiation was measured using the date patients received their first e-script. Continuous variables were compared using Mann-Whitney test. Categorical variables were compared using Fisher's exact test. Analyses were conducted using STATA SE 16.0 (Stata Corp., College Station, TX). This study was reviewed and approved by University of Mississippi Medical Center's Institutional Review Board (IRB).

\section{Results}

During the evaluation time period, 70 individuals newly diagnosed with HIV were evaluated for treatment at OAHCC. Sixty-three patients were included in the analysis. Individuals who did not have a detectable viral load at their initial HIV care visit were excluded $(n=2)$. Five patients were excluded from the analysis because

Table 1 Demographic and clinical characteristics of patients newly diagnosed with HIV treated at OAHCC, January 1, 2016-December 31, 2018

\begin{tabular}{|c|c|c|c|c|}
\hline & All patients, $n$ (\%) & Rapid-ART group, $n$ (\%) & Non-Rapid ART group, $n$ (\%) & $\begin{array}{l}P \text {-value for comparison } \\
\text { of rapid versus non-rapid } \\
\text { groups }(\alpha=0.05)\end{array}$ \\
\hline Number & 63 & 16 & 47 & \\
\hline \multicolumn{5}{|l|}{ Age (in years) } \\
\hline Median Age (range) & $27(20-61)$ & $29.5(21-53)$ & $27(20-61)$ & 0.38 \\
\hline Sex (gender when available) & & & & 0.50 \\
\hline Male & $53(84 \%)$ & $14(88 \%)$ & $39(83 \%)$ & \\
\hline Female & $8(13 \%)$ & $2(13 \%)$ & $6(13 \%)$ & \\
\hline Transgender female & $2(3 \%)$ & $0(0)$ & $2(4 \%)$ & \\
\hline Race/ethnicity & & & & 0.32 \\
\hline Black/African American & $57(91 \%)$ & $16(100 \%)$ & $41(87 \%)$ & \\
\hline Hispanic/latinx & $3(4.8 \%)$ & $0(0)$ & $3(6 \%)$ & \\
\hline White & $3(4.8 \%)$ & $0(0)$ & $3(6 \%)$ & \\
\hline Sexual orientation & & & & 0.35 \\
\hline Gay/homosexual & $35(56 \%)$ & $11(69 \%)$ & $24(51 \%)$ & \\
\hline Heterosexual & $16(25 \%)$ & $2(13 \%)$ & $14(30 \%)$ & \\
\hline Bisexual & $12(19 \%)$ & $3(19 \%)$ & $9(19 \%)$ & \\
\hline Insurance & & & & 0.45 \\
\hline Uninsured & $36(57 \%)$ & $8(50 \%)$ & $28(60 \%)$ & \\
\hline Commercial & $20(32 \%)$ & $7(44 \%)$ & $13(28 \%)$ & \\
\hline $\begin{array}{l}\text { Government Ins. (medicaid/ } \\
\text { medicare) }\end{array}$ & $7(11 \%)$ & $1(6 \%)$ & $6(12 \%)$ & \\
\hline Substance use & & & & 0.84 \\
\hline Marijuana & $14(22 \%)$ & $3(18 \%)$ & $11(65 \%)$ & \\
\hline Other (cocaine, opioids, etc.) & $3(5 \%)$ & $1(5 \%)$ & $2(12 \%)$ & \\
\hline \multicolumn{5}{|c|}{ Baseline CD4+, HIV RNA (mean, \pm SD) } \\
\hline CD4+T cell count (cells/ $\mu \mathrm{l})$ & $446( \pm 290.25)$ & $603( \pm 323.74)$ & $393( \pm 260.64)$ & 0.009 \\
\hline HIV RNA (copies/mL) & 49,768 (130-10 million) & 22,800 (500-10 million) & 60,199 (130-3.8 million) & 0.076 \\
\hline
\end{tabular}


Table 2 Unadjusted time from diagnosis to clinical milestones among patients newly diagnosed with HIV treated at OAHCC $(n=63)$ by year, 2016-2018

\begin{tabular}{llll}
\hline & $\mathbf{2 0 1 6}$ & $\mathbf{2 0 1 7}$ & $\mathbf{2 0 1 8}$ \\
\hline Outcomes & & 26 & 17 \\
Diagnosed, $n$ & 20 & $26(100 \%)$ & $17(100 \%)$ \\
Started ART, $n(\%)$ & $20(100 \%)$ & $9(35 \%)$ & $5(29 \%)$ \\
Met rapid definition, $n(\%)$ & $2(10 \%)$ & $26(100 \%)$ & $16(94 \%)$ \\
$\%$ In care $\leq 1$ year & $18(90 \%)$ & $12(1-31)$ & $9(0-293)$ \\
Diagnosis to care entry, median number of days (range) & $17.5(0-596)$ & $0(0-24)$ & $0(0-81)$ \\
First care visit to ART start, median number of days (range) & $0(0-13)$ & $47.5(21-240)$ & $47(0-212)$ \\
ART start to first HIV RNA $<200$ cells/mL & $39(21-145)$ & $66.5(21-252)$ & $77(6-322)$ \\
Diagnosis to HIV RNA $<200$ cells $/ \mathrm{mL}$ & $71.5(34-644)$ & &
\end{tabular}

they transferred care immediately following diagnosis $(n=2)$ or they did not return for their initial visit for HIV care $(n=3)$. Of the patients who met the criteria for analysis, $27 \%$ were rapid ART starters.

Demographic and behavioral characteristics of the sample population are shown in Table 1 . Majority of the sample were men $(87 \%)$, identified as non-heterosexual (75\%) and were Black/African American (91\%). The median age was 27-years old (IQR, 20-61). Fiftyseven percent of patients (36/63) were uninsured and received Ryan White-funded HIV services; only $31 \%$ had commercial health insurance coverage. Mean baseline viral load was $337,280( \pm 134,1230)$ copies/mL and the mean CD4+ T cell count was $446( \pm 290.25)$ cells/ $\mu \mathrm{l}$. Initial CD4+ T cell counts were found to be statistically significant in rapid starters compared to non-rapid starters $(p=0.009)$. There were no statistical differences for age, race, sex, sexual orientation, drug use or health insurance status between rapid ART starters and nonrapid starters.

Unadjusted clinical milestones per year are described in Table 2. Of the 20 individuals diagnosed with HIV infection in 2016, only two were rapid ART starters. Seventy percent $(14 / 20)$ of patients were linked to care with a provider within 30 days. In 2017, 26 patients were diagnosed with HIV, 96\% (25/26) were linked to care within 30 days, and 35\% (9/26) started ART within 7 days. Seventeen patients were diagnosed with HIV in 2018, of which $88 \%$ (15/17) were linked to care within 30 days and 29\% (5/17) were rapid ART starters. The median time to linkage for the entire sample was 12 days and was significantly shorter for rapid ART starters compared to non-rapid starters ( 5.5 days vs 15 days; $\mathrm{p}<0.001$ ).

Group comparison of virologic outcomes are presented in Table 3. Median time from initial HIV diagnosis to ART start was 5.5 days for rapid ART initiators (vs.
20 days; $\mathrm{p}<0.001$ ). The median time from diagnosis to viral suppression decreased from 77 days in non-rapid starters to 55 days in rapid ART starters $(\mathrm{p}=0.03)$. Time from ART start to viral suppression was not statistically different between rapid starters and non-rapid starters (50 vs. 46 days; $\mathrm{p}=0.35$ ).

\section{Discussion}

Our findings provide evidence of successful implementation and delivery of a rapid ART program in community-based clinic in the Deep South. Acceptance of rapid ART was high and initiation proved to be feasible despite existing structural barriers. Of 63 individuals diagnosed with HIV from 2016 to 2018, only 5 individuals $(8 \%)$ had an initial CD4+ T cell count $<200$ cells/ $\mu \mathrm{l}$, indicating more recent HIV infections than those who may have been diagnosed previously. As a result of this program, individuals who were rapid ART starters achieved faster linkage to care and significant decreases in the time from the initial care visit to ART start as well as the time from initial diagnosis to viral suppression. This is consistent with a review of the literature that includes meta-analyses, prospective, observational and randomized studies.

To our knowledge, this is the first paper to report on the experience of rapid ART initiation in Mississippi. Our evaluation indicates that this demonstration project supports the use of rapid ART as a feasible approach in places that lack local government-mandated and funded initiatives. Rapid ART in this community-based clinic resulted in shorter times to linkage to care with an HIV provider and faster access to ART prescriptions. Rapid ART also serves as a tangible resource for addressing the Ending the HIV Epidemic initiative in the U.S. 
Table 3 Unadjusted virologic outcomes of patients receiving HIV care at OAHCC by Rapid-ART Status, 2016-2018

\begin{tabular}{llll}
\hline & $\begin{array}{l}\text { Rapid ART initiators (received } \\
\text { a prescription } \leq 7 \text { days of diagnosis), } \\
\text { (IQR) }\end{array}$ & $\begin{array}{l}\text { Non-rapid initiators (received } \\
\text { a prescription }>\text { 7 days of diagnosis), } \\
\text { (IQR) }\end{array}$ & $\begin{array}{l}P \text {-value (a=0.05) } \\
\text { Outcomes }\end{array}$ \\
Diagnosed, $n$ & 16 & 47 & $<0.001$ \\
Diagnosis to care entry, median (range) & $5.5(0-7)$ & $15(0-596)$ & $<0.001$ \\
First care visit to ART start, median (range) & $5.5(0-7)$ & $20(8-608)$ & 0.35 \\
ART start to HIV RNA $<200$ cells/mL & $50(21-172)$ & $46(21-240)$ & 0.03 \\
Diagnosis to HIV RNA $<200$ cells/mL & $55(26-179)$ & $75(6-644)$ & \\
\hline
\end{tabular}

Benefits achieved by rapid ART initiation were first examined in the CASCADE Randomized Clinical Trial conducted in sub-Saharan Africa. Viral suppression was achieved by $50.4 \%$ of same day starters versus $34.3 \%$ in the SOC group [4]. Linkage to care was also higher $(68 \%)$ for same day starters compared to those in SOC (43.1\%). This study supports the use of rapid ART initiation in high-risk patient settings. In an unblinded, randomized trial designed to test and evaluate the use of a rapid service delivery intervention findings suggest that those who benefitted from rapid ART the most were individuals who otherwise would not have initiated care [17]. While time from ART start to virologic suppression between groups in this evaluation was not significant, previous studies support that rapid ART initiation is beneficial to high-risk populations $[2,4,18]$. These non-significant findings may be attributed to the unknown period between patients being provided with a prescription for ART and actually starting their medication, due in part by delay caused by third party payers who require a viral load confirmation.

The success of rapid ART initiation at OAHCC is largely a result of the HIV diagnosis same-day referral partnership between OAHCC and MSDH. Despite the lack of ART starter packs that were provided to patients in previously mentioned demonstration projects, this program was still successful in satisfying ADAP requirements and lessening time from diagnosis to ART start by taking advantage of existing medication assistance programs when needed. The staff is comprised of three part-time physicians, one parttime and one full-time nurse practitioner, three case managers and several nurses dedicated to patient care. In addition, OAHCC is equipped with resources that address micro-barriers such as food insecurity and lack of transportation. Each individual who initiated ART therapy returned for their four week follow-up visit with a provider. This is a testament of the strong social support of OAHCC to maintain retention in care.

This evaluation has several limitations. Individuals who were classified as rapid ART starters may have had less barriers to care than individuals who were non-rapid starters, resulting in better outcomes for the rapid ART group. OAHCC lacks an on-site pharmacy; therefore, we were unable to verify that patients who received an ART prescription, filled the prescription and started taking antiretrovirals immediately. The ADAP process, which requires that individuals newly diagnosed with HIV be verified through the MSDH HIV reporting system and have initial HIV lab results before medication will be dispensed, contributed to a delay of 2-3 weeks between when the prescription was written and the patient received the medication. Moreover, the number of ART manufacturers that provide immediate access to medications while ADAP is pending is limited.

\section{Conclusions}

Evidence from this evaluation supports the use of rapid ART initiation after an initial HIV diagnosis, including same-day therapy. This program provides evidence for the feasibility of Rapid ART initiation in hard-toreach populations, including men who have sex with men (MSM). Future directions include implementing a government-funded initiative to help address the HIV disparities that exist throughout the state and to extend rapid initiation services to rural areas. Improvements to the ADAP medication process could increase medication access for newly diagnosed patients.

\footnotetext{
Abbreviations

ART: Antiretroviral therapy; e-script: Electronic prescription; PLWH: People living with HIV; WHO: World Health Organization; IAS-USA: International AIDS Society USA; DHHS: Department of Health and Human Services; ATL: Atlanta; NO: New Orleans; SF: San Francisco; DC: Washington D.C.; FF: Fast forward; SOC: Standard of Care; ADAP: AIDS Drug Assistance Program; eHARS: Electronic HIV/AIDS Reporting System; OAHCC: Open Arms Healthcare Center; CBO: Community-based Organization; LGBT: Lesbian, Gay, Bisexual and
} 
Transgender; MSDH: Mississippi State Department of Health; STD: Sexually Transmitted Disease; IRB: Institutional Review Board; MSM: Men who have sex with men.

\section{Acknowledgements}

Lori Ward, PhD, MS - for her statistical expertise.

\section{Authors' contributions}

CG was involved in obtaining IRB approval and data analysis. CG and KB both wrote the first draft of the manuscript. LM, SM, JB and JP reviewed and edited the manuscript. All authors read and approved the final manuscript.

\section{Funding}

No funding was received for the preparation of this manuscript.

\section{Availability of data and materials}

Data availability must be on an "upon reasonable request" basis made to the corresponding author.

\section{Ethics approval and consent to participate}

This study was review and approved by the University of Mississippi Medical Center Institutional Review Board. This included a waiver of consent, permitting access to identified health data.

\section{Consent for publication}

Not applicable.

\section{Competing interests}

The authors declare that they have no competing interests.

\section{Author details}

${ }^{1}$ Department of Population Health Science, John D. Bower School of Population Health, University of Mississippi Medical Center, 2500 N State Street, Jackson, MS 39216, USA. ${ }^{2}$ Division of Infectious Diseases, School of Medicine, University of Mississippi Medical Center, Jackson, MS, USA. ${ }^{3}$ Open Arms Healthcare Center, Jackson, MS, USA.

Received: 3 April 2020 Accepted: 26 September 2020

Published online: 08 October 2020

\section{References}

1. Coffey S, Bacchetti P, Sachdev D, Bacon O, Jones D, Ospina-Norvell C, Torres S, Lynch E, Camp C, Mercer-Slomoff R, Lee S, Christopoulos K, Pilcher C, Hsu L, Jin C, Scheer S, Havlir D, Gandhi M. RAPID antiretroviral therapy: high virologic suppression rates with immediate antiretroviral therapy initiation in a vulnerable urban clinic population. AIDS. 2019;33(5):825-32.

2. Ford N, Migone C, Calmy A, Kerschberger B, Kanters S, Nsanzimana S, Mills EJ, Meintjes G, Vitoria M, Doherty M, Shubber Z. Benefits and risks of rapid initiation of antiretroviral therapy. AIDS. 2018;32(1):17-23.

3. Boyd M, Boffito M, Castagna A, Estrada V. Rapid initiation of antiretroviral therapy at HIV diagnosis: definition, process, knowledge gaps. HIV Medicine 2019:20(S1):3-11.

4. Labhardt ND, Ringera I, Lejone TI, Klimkait T, Muhairwe J, Amstutz A, Glass TR. Effect of offering same-day ART vs usual health facility referral during home-based HIV testing on linkage to care and viral suppression among adults with HIV in lesotho: the CASCADE randomized clinical TrialEffect on viral suppression of same-day ART vs care referral after home HIV testing in LesothoEffect on viral suppression of same-day ART vs care referral after home HIV testing in Lesotho. JAMA. 2018;319(11):1103-12.

5. Pilcher CD, Ospina-Norvell C, Dasgupta A, Jones D, Hartogensis W, Torres S, Calderon F, Demicco E, Geng E, Gandhi M, Havlir DV, Hatano H. The effect of same-day observed initiation of antiretroviral therapy on HIV viral load and treatment outcomes in a US public health setting. J Acquir Immune Defic Syndr. 2017;74(1):44-51.
6. Colasanti J, Sumitani J, Mehta CC, Zhang Y, Nguyen ML, del Rio C, Armstrong WS. Implementation of a rapid entry program decreases time to viral suppression among vulnerable persons living with HIV in the Southern United States. Open Forum Infect Dis. 2018;5:6.

7. Halperin J, Butler I, Conner K, Myers L, Holm P, Bartram L, Van Sickels N. Linkage and antiretroviral therapy within 72 hours at a federally qualified health center in New Orleans. AIDS Patient Care STDs. 2018;32(2):39-41.

8. HIV.gov What is 'Ending the HIV Epidemic: A Plan for America?'. https ://www.hiv.gov/federal-response/ending-the-hiv-epidemic/overview. Accessed 21 May.

9. UNAIDS 90-90-90: An ambitious treatment target to help end the AIDS epidemic. https://www.unaids.org/en/resources/909090. Accessed 21 May.

10. Panel on Antiretroviral Guidelines for Adults and Adolescents. Guidelines for the Use of Antiretroviral Agents in Adults and Adolescents with HIV; Department Of Health And Human Services. https://www.aidsinfo.nih. gov/ContentFiles/AdultandAdolescentGL.pdf.

11. Cohen MS, McCauley M, Gamble TR. HIV treatment as prevention and HPTN 052. Curr Opinion HIV AIDS. 2012;7(2):99-105.

12. Cohen MS, Chen YQ, McCauley M, Gamble T, Hosseinipour MC, Kumarasamy N, Hakim JG, Kumwenda J, Grinsztejn B, Pilotto JHS, Godbole SV, Chariyalertsak S, Santos BR, Mayer KH, Hoffman IF, Eshleman SH, Piwowar-Manning E, Cottle L, Zhang XC, Makhema J, Mills LA, Panchia R, Faesen S, Eron J, Gallant J, Havlir D, Swindells S, Elharrar V, Burns D, Taha TE, Nielsen-Saines K, Celentano DD, Essex M, Hudelson SE, Redd AD, Fleming TR. Antiretroviral therapy for the prevention of HIV-1 transmission. N Engl J Med. 2016;375(9):830-9.

13. Rodger AJ, Cambiano V, Bruun T, Vernazza P, Collins S, Degen O, Corbelli GM, Estrada V, Geretti AM, Beloukas A, Raben D, Coll P, Antinori A, Nwokolo N, Rieger A, Prins JM, Blaxhult A, Weber R, Van Eeden A, Brockmeyer NH, Clarke A, Del Romero Guerrero J, Raffi F, Bogner JR, Wandeler G, Gerstoft J, Gutierrez F, Brinkman K, Kitchen M, Ostergaard L, Leon A, Ristola M, Jessen H, Stellbrink HJ, Phillips AN, Lundgren J. Risk of HIV transmission through condomless sex in serodifferent gay couples with the HIV-positive partner taking suppressive antiretroviral therapy (PARTNER): final results of a multicentre, prospective, observational study. Lancet. 2019;393(10189):2428-38.

14. Bavinton BR, Pinto AN, Phanuphak N, Grinsztejn B, Prestage GP, ZablotskaManos IB, Jin F, Fairley CK, Moore R, Roth N, Bloch M, Pell C, McNulty AM, Baker D, Hoy J, Tee BK, Templeton DJ, Cooper DA, Emery S, Kelleher A, Grulich AE. Viral suppression and HIV transmission in serodiscordant male couples: an international, prospective, observational, cohort study. Lancet HIV. 2018;5(8):e438-e447447.

15. Haines CF, Fleishman JA, Yehia BR, Lau B, Berry SA, Agwu AL, Moore RD, Gebo KA. Closing the gap in antiretroviral initiation and viral suppression: time trends and racial disparities. J Acqu Immune Defic Syndr. 2016:73(3):340-7.

16. Olsen HA, Sarkodie E, Coleman M, Davies M, Henn S, Health W-W. Fast forward to viral suppression: immediate initiation of ARVs following Reactive HIV+ test result or engagement in HIV Care for the first time at a community health center in Washington. In IAPAC Miami: DC; 2018.

17. Rosen S, Maskew M, Fox MP, Nyoni C, Mongwenyana C, Malete G, Sanne I, Bokaba D, Sauls C, Rohr J, Long L. Initiating antiretroviral therapy for HIV at a patient's first clinic visit: the RapIT randomized controlled trial. PLoS Med. 2016:13(5):e1002015.

18. McNeely J, Kumar PC, Rieckmann T, Sedlander E, Farkas S, Chollak C, Kannry JL, Vega A, Waite EA, Peccoralo LA, Rosenthal RN, McCarty D, Rotrosen J. Barriers and facilitators affecting the implementation of substance use screening in primary care clinics: a qualitative study of patients, providers, and staff. Addict Sci Clin Pract. 2018;13(1):8.

\section{Publisher's Note}

Springer Nature remains neutral with regard to jurisdictional claims in published maps and institutional affiliations. 